\title{
Fatigue analysis and life predictions of Forged steel and Powder Metal connecting rods
}

\author{
Guduri Tirupati Reddy ${ }^{1}$, Chidurala Srinivas ${ }^{2}$ \\ ${ }^{1}$ (PG Student, Mechanical Engineering Dept., Vaageswari College of Engineering, Karimnagar, India \\ ${ }^{2}$ (Professor, Mechanical Engineering Dept., Vaageswari College of Engineering, Karimnagar, India
}

\begin{abstract}
The report investigates on fatigue behavior of forged steel connecting rods. They must be capable of transmitting axial tension and compression loads. Altair Hyper works software is used for applying tension and compression loads, Altair Hyper mesh for preprocessing, Altair Radioss for solving tension and compression analysis at the same time fatigue analysis for checking the life of the material based on tension and compression condition are solved. Conclusion is based on the result of material life. Modeling incorporated three-dimensional geometry, tension and compression loading, and symmetry conditions. 3-D model geometry was developed in CATIA V5R19. These analyses were performed iteratively at different element lengths until the solution obtained appropriate accuracy. Convergence of stresses were observed, as the mesh size was successively refined. The element size of $1.27 \mathrm{~mm}$ was finally considered. The result obtained were discussed and reported.
\end{abstract}

Keywords: forged steel, connecting rods Altair Hyper works element size.

\section{Introduction}

The function of connecting rod is to translate the transverse motion to rotational motion. It is a part of the engine, which is subjected to millions of repetitive cyclic loadings. It should be strong enough to remain rigid under loading, and be light enough to reduce the inertia forces produced when the rod and piston stop, change directions and start again at the end of each stroke. The connecting rod should be designed with high reliability. It must be capable of transmitting axial tension, axial compression, and bending stresses caused by the thrust and pull on the piston, and by centrifugal force without bending or twisting. The connecting rod experiences inertia forces plus direct forces that produce bending in a plane perpendicular and parallel to the crankshaft longitudinal axis. Connecting rod is typically designed for infinite life. Failures of connecting rods are often caused by bending loads acting perpendicular to the axes of the two bearings. Failure in the shank section as a result of these bending loads occurs in any part of the shank between piston-pin end and the crankpin end [1]. At the crank end fracture, can occur at the threaded holes or notches for the location of headed bolts. Pin-end failures can occur from bore against a fitted bushing.

\section{Modeling Of Connecting Rods}

A 3-D model is designed in CATIA V5 and then imported in to Altair Hypermesh, after completing preprocessing it is solved using ALTAIR RADIOSS. Dimensions of the connecting rod were taken from three different connecting rods and the averages of these dimensions are used to generate the model. Due to symmetry of the geometry, the component was first half modeled, and then the entire geometry was created by reflecting (mirror imaging) the half geometry. The density of $7.9 \mathrm{e}-09 \mathrm{~kg} / \mathrm{mm} 3$ was used as material property in the FEA model. It is an indication of the FEA model accuracy [2]. A hexahedral element for different sizing of mesh \& Hexamesh was used for the solid geometry, as this was the default option by ALTAIR RADIOSS for any 3-D analysis. Sensitivity analysis was performed to obtain the optimum element size of $1.27 \mathrm{~mm}$ was finally considered. Total numbers of elements generated are 80016 and total numbers of nodes generated are 130210 at $1.27 \mathrm{~mm}$ element length. The solid meshing module allows user to quickly generate high quality meshes for multiple volumes. After meshing is done for complete connecting rod required material must be applied for existing mesh. material collector using Hypermesh interface which consist of Matfat card which is useful to conduct fatigue test for stress - life (S-N) \& strain - life (E-N) by giving material properties such as young's modulus, Poisson's Ratio, yield strength, ultimate tensile strength [3].

\section{Type of Analysis}

Tension and compression loads were applied as pressure on the bearing surfaces of the connecting rod. Under actual service condition, pin end experiences tension by the piston pin causing distribution of pressure along the upper half of the inner diameter, which is approximated by the cosine function. In compression, the piston pin compresses the bearings against the pin end inner diameter, causing uniform distribution of pressure. 
The same phenomenon of pressure distribution caused by the crankshaft was experimentally measured on the crank end of the connecting rod Shown in Fig.1.The connecting rod was constrained in all six degrees of freedom from the bearing surfaces on one end and pressure was applied at the other end [4]. Only longitudinal loading direction was considered as this is the primary loading direction. The typical engine parameters for four cylinder engine are given in Table 1.

Table 1: Typical engine parameters of four-cylinder engine

\begin{tabular}{|l|l|}
\hline Engine parameters & Dimensions \\
\hline Connecting rod length & $157 \mathrm{~mm}$ \\
\hline Crankshaft radius & $52 \mathrm{~mm}$ \\
\hline Crank to C.G distance & $42.50 \mathrm{~mm}$ \\
\hline Engine speed & $4000-8000 \mathrm{rpm}$ \\
\hline Maximum firing pressure & $53.70 \mathrm{ATM}$ \\
\hline Maximum compression pressure & $10.00 \mathrm{ATM}$ \\
\hline Piston diameter & $87.5 \mathrm{~mm}$ \\
\hline Piston assembly mass & $585.00 \mathrm{~g}$ \\
\hline Forged steel connecting rod weight & $430.00 \mathrm{~g}$ \\
\hline
\end{tabular}

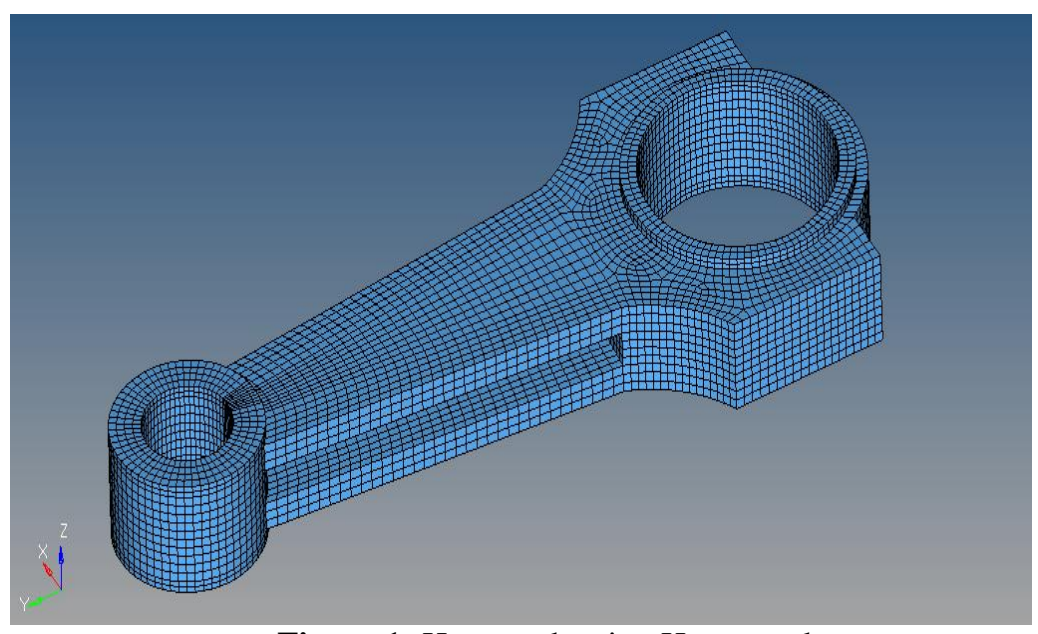

Figure 1: Hexamesh using Hypermesh

Table 2: Summary of connecting rod FE analysis load parameters.

\begin{tabular}{|c|c|c|c|c|}
\hline \multirow{2}{*}{ Parameter } & \multicolumn{2}{|c|}{ Crank end loading } & \multicolumn{2}{c|}{ Pin end loading } \\
\cline { 2 - 5 } & Tension & Compression & Tension & Compression \\
\hline Load magnitude & $26688 \mathrm{~N}$ & $26688 \mathrm{~N}$ & $26688 \mathrm{~N}$ & $26688 \mathrm{~N}$ \\
\hline \multirow{2}{*}{ Load distribution } & Cosine distribution & Uniform & Cosine & Uniform \\
& over $180^{\circ}$ & $180^{\circ}$ & $\begin{array}{c}0^{\circ} \\
\text { distribution over } \\
180^{\circ}\end{array}$ & $\begin{array}{c}\text { distribution over } \\
180^{\circ}\end{array}$ \\
\hline Pressure on the surface & $35.7 \mathrm{MPa}$ & $32.4 \mathrm{MPa}$ & $72.6 \mathrm{MPa}$ & $65.9 \mathrm{MPa}$ \\
\hline
\end{tabular}

\section{Load And Stress Analysis}

Connecting rods are submitted to mass and gas forces. The superposition of these two forces produces axial force which acts on the connecting rod. Connecting rods also experience bending moments due to eccentricities, crankshaft and rotational mass forces. Axial loading can be calculated by the knowledge of engine pressure and rotational speed, whereas bending moment can be determine by strain analysis in an engine. Critical areas of failure are the transition regions from the small end to the shank and from the shank to the big end. Local stress amplitudes are obtained for the critical areas. They concluded that an error in the moment of inertia of connecting rod using this model could predict incorrect engine forces and dynamics [5]. With the actual connecting rod model, the inertia forces of the distributed mass model become more complicated to analyze. The small end of the rod has a reciprocating motion along the bore, whereas, the big end of the rod moves in rotational motion. However, the center of rod mass path describes an ellipse, which makes it difficult to analyze. Therefore, a two lump mass connecting rod model was introduced for simplification. The connecting rod is divided into reciprocating and rotating masses so that the distributed connecting rod mass is replaced by 
lumped masses at each end located at the bore center [6]. The following equations have to be satisfied to make the rod model equivalent to the actual rod model:

$$
\begin{aligned}
& \mathrm{mc}=\mathrm{mc}, \mathrm{a}+\mathrm{mc}, \mathrm{b} \\
& \mathrm{mc}, \mathrm{a} \mathrm{L} 1=\mathrm{mc}, \mathrm{b} \mathrm{L} 2 \\
& \mathrm{Jc}=\mathrm{mc}, \mathrm{a} \mathrm{L} 12+\mathrm{mc}, \mathrm{b} \mathrm{L} 22+\mathrm{Jf}
\end{aligned}
$$

Where,

$\mathrm{mc}$ is the mass of connecting rod,

$\mathrm{mc}, \mathrm{a}$ is the reciprocation mass of connecting rod,

$\mathrm{mc}, \mathrm{b}$ is the rotating mass of connecting rod,

$\mathrm{L} 1$ is the distance from connecting rod mass center to piston pin center,

L2 are the distance from connecting rod mass center to crank pin center,

$\mathrm{Jc}$ is the actual moment of inertia,

$\mathrm{Jf}$ is the inertia error.

\section{Mesh Size Sensitivity Analysis}

To recognize the effect of element size on the stresses, mesh size sensitivity analysis was carried [7]. The stress changes as a result of element size changes. These analyses were performed iteratively at different element lengths until the solution obtained appropriate accuracy. For this analysis, the rod was constrained at the pin end and cosine distribution pressure was applied at the crank end. For the first analysis, a $7.77 \mathrm{~mm}$ default mesh size was used and von mises stresses were obtained at three different locations. For the second iteration, a mesh size of $2.54 \mathrm{~mm}$ was used, and for the third iteration a mesh size of $1.52 \mathrm{~mm}$ was used. For final iteration, an element length of $1.27 \mathrm{~mm}$ was used. Table 2 summarizes the results of the convergence of stresses at different locations. shown in Fig.2

Mesh sensitivity analysis is done by using different mesh sizes as mentioned in Table 2. As per the mesh sensitivity the mesh size is given accurate results Shown in Fig.3. In finite element analysis based on number of nodes these results are accurate because when large mesh size is used it may not give good results because of its less number of nodes, so that it will not capture high stress location and displacement location[8]. For checking the fatigue behavior of two materials same load is used as mentioned above. By taking the load of $26688 \mathrm{~N}$, converting as a pressure based on tension and compression values and applying to the connecting rod [9]. Pressure load is applied because load should be radial shown in Fig.4. Compression values and applying to the connecting rod and is shown in Fig.5

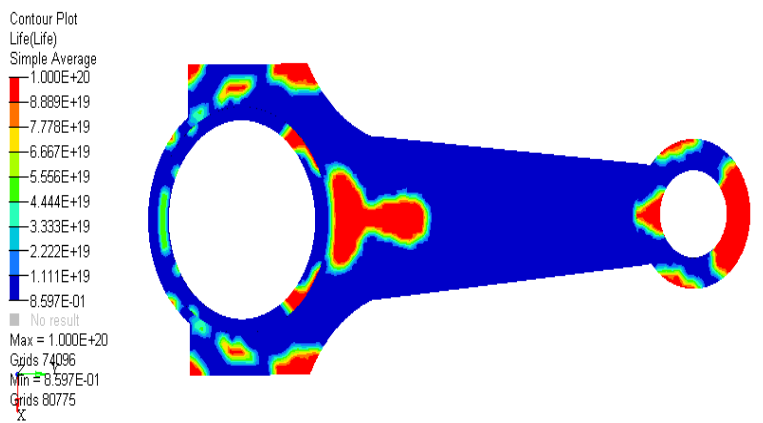

Figure 2: Life of the forged steel component is 1E20 cycles

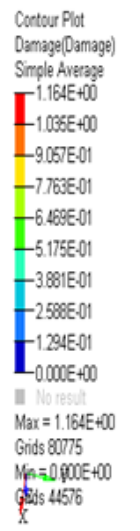

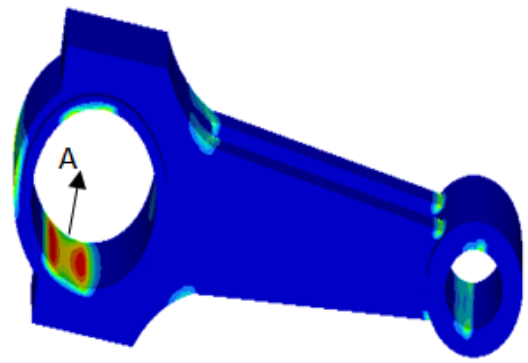

Figure 3: forged steel rod damage (A) 

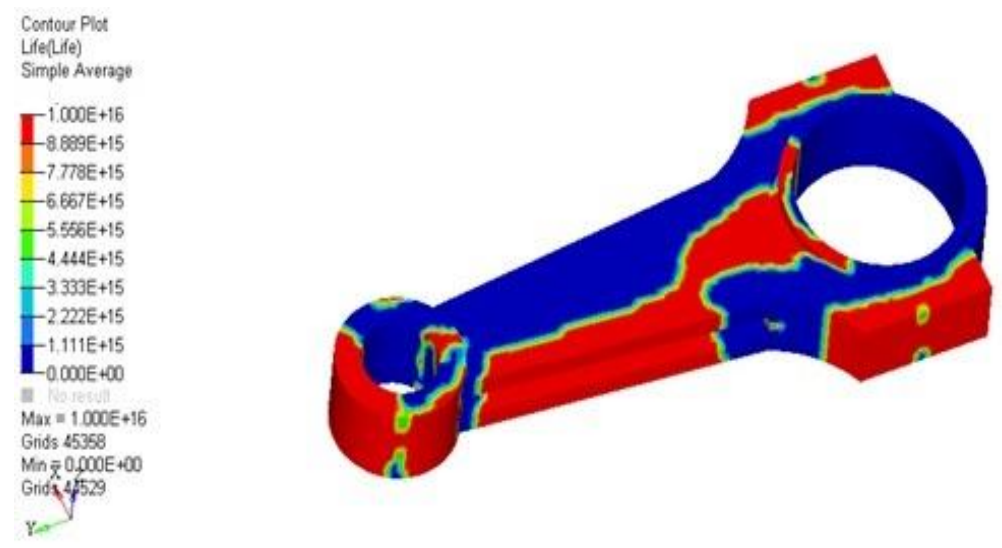

Figure 4: Life of the powder metal component is 1E16 cycles
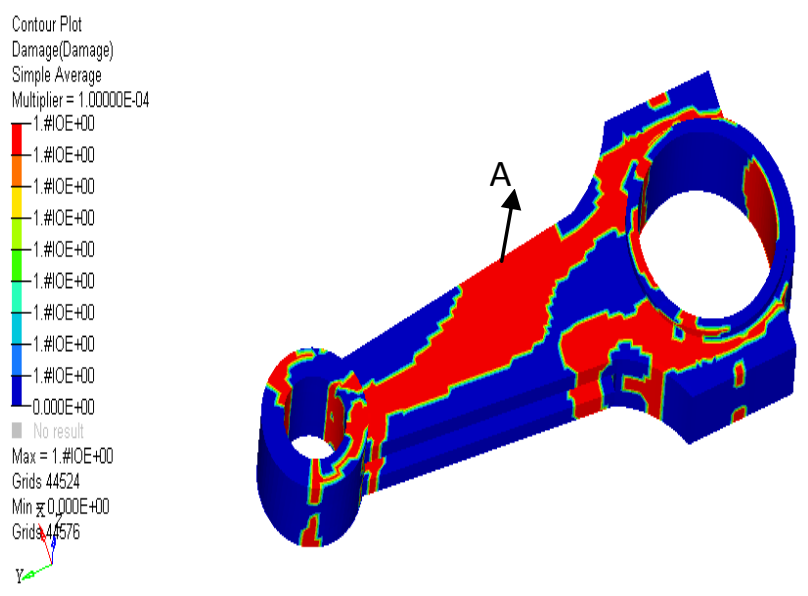

Figure 5: Powder metal connecting rod get damages (A)

\section{Results And Discussion}

Materials tests are often classified as monotonic or cyclic. Both kinds of these tests are used to characterize the mechanical properties of metals, composites and many other materials, as well as components made from these materials [10]. The tension and compression are examples of monotonic tests are shown in Table 3. in these tests, an increasing load (positive or negative) is applied to the specimen to identify its yield strength, ultimate strength and other properties [11]. Cyclic tests apply oscillating loads, often until specimen failure, using load schemes that may involve either cyclic tension, compression or a combination of these two properties are shown in Table. 4

Table 3: Summary of montonic properties for forged steel.

\begin{tabular}{|c|c|c|}
\hline Montonic properties & Forged steel & Powder metal \\
\hline Modulus of elasticity, E, GPa & 201 & 199 \\
\hline Yield strength, YS, MPa & 700 & 588 \\
\hline Ultimate strength, Su MPa & 938 & 866 \\
\hline Percentage elongation, \%EL (\%) & $24 \%$ & $23 \%$ \\
\hline Percentage reduction in area, \%RA & $42 \%$ & $23 \%$ \\
\hline Strength coefficient, K, MPa & 1,400 & 1379 \\
\hline Strain hardening exponent, n & 0.122 & 0.152 \\
\hline True fracture strength, sf, MPa & 1,266 & 994 \\
\hline True fracture ductility ef (\%) & $54 \%$ & $26 \%$ \\
\hline Hardness & 28 & 20 \\
\hline
\end{tabular}


Table 4: Summary of fatigue material cyclic properties for forged steel.

\begin{tabular}{|c|c|c|}
\hline Cyclic properties & Forged steel & Powder metal \\
\hline Fatigue strength coefficient, MPa & 1188 & 1493 \\
\hline Fatigue strength exponent & -0.0711 & -0.1032 \\
\hline Fatigue ductility coefficient & 0.3576 & 0.1978 \\
\hline Fatigue ductility exponent & -0.5663 & 0.5304 \\
\hline Cyclic yield strength, Mpa & 620 & 609 \\
\hline Cyclic strength coefficient, MPa & 1397 & 2005 \\
\hline Cyclic strain hardening exponent & 0.1308 & 0.1917 \\
\hline True fracture strength, sf & 423 & 334 \\
\hline Average, GPa & 204 & 197 \\
\hline
\end{tabular}

\section{Conclusions}

In this study, Experimental results, observations and analysis performed gives the following conclusions can be drawn:

1. Results of tensile and compressive test of connecting rod, which shows clearly that forged steel has $20 \%$ more life than the other metal connecting rods.

2. As per fatigue test, forged steel life shows $1 \mathrm{E} 20$ cycles. By this it has been proved that forged steel is better replacement on other metals.

3. 3. Linear elastic finite element analysis of the forged steel connecting rod under axial loading indicated the two transition regions (crank end to the shank and pin end to the shank) to be the critical regions.

\section{Future Scope Of Work}

Recent developments of C-70 and micro alloyed steels, Fatigue analysis and life predictions can be conducted for the C-70 and micro alloyed steel connecting rods using tensile, compressive and fatigue test are to be conducted.

\section{References}

[1] Araki, S., Satoh, T., and Takahara, H., Application of powder forging to automotive connecting rods, Kobelco Technology Review, 16, 1993, 20-24.

[2] ASTM Standard E83-96, Standard practice for verification and classification of extensometers, Annual Book of ASTM Standards, 03.01, 198-206,1997.

[3] ASTM Standard E606-92, Standard practice for strain-controlled fatigue testing, Annual Book of ASTM Standards, 03.01, 523-537,1997.

[4] ASTM Standard E1012-93a, Standard practice for verification of specimen alignment under tensile loading, Annual Book of ASTM Standards, 03.01,699-706,1997.

[5] ASTM Standard E8-96a, Standard test methods for tension testing of metallic materials, Annual Book of ASTM Standards, 03.01, 56-76,1997.

[6] ASTM Standard E739-91, Standard practice for statistical analysis of linear or linearized stress-life (S-N) and strain life $(\varepsilon-N)$ fatigue data, Annual Book of ASTM standards, 03.01, 615-621,1995.

[7] ASTM Standard E646-93, Standard test method for tensile strain-hardening exponents (n-values) of metallic sheet materials, Annual Book of ASTM Standards, 03.01, 550-556,1997.

[8] Athavale, S. and Sajanpawar, P. R., Studies on some modeling aspects in the finite element analysis of small gasoline engine components, SAE of Japan, 911271, 379-389,1991.

[9] Balasubramanian, B., Svoboda, M., and Baur, W., Structural optimization of I.C. engines subjected to mechanical and thermal loads, Computer Methods in Applied Mechanics and Engineering, 89(1-3), 337-360,1991.

[10] Banerji, S. K., Application of microalloyed forgings for heavy-duty diesel-engine connecting rods and other components, Mineral, Metals and Materials Society, 375- 389,1996.

[11] Beretta, S., Blarasin, A., Endo, M., Giunti. T., and Murakami, Y., Defect tolerant design of automotive components, International Journal of Fatigue, 19(4), 319-333,1997.. 